\title{
Monitoring dan Kontrol Sistem Irigasi Berbasis IoT Menggunakan Banana Pi
}

\author{
Andrie Wijaya, dan Muhammad Rivai \\ Departemen Teknik Elektro, Fakultas Teknologi Elektro, Institut Teknologi Sepuluh Nopember (ITS) \\ e-mail:muhammad_rivai@ee.its.ac.id
}

\begin{abstract}
Abstrak - Saat ini metode pengaliran air atau irigasi dilakukan secara manual. Petani harus menyiram tanaman satu persatu sehingga tidak efisien dalam hal energi, waktu, dan ketersediaan air sehingga dapat menurukan hasil panen. Internet of Things merupakan konsep dan metode untuk kontrol jarak jauh, monitoring, pengiriman data, dan berbagai tugas lainnya. IoT terhubung dengan suatu jaringan sehingga dapat di akses di mana saja yang dapat mempermudah berbagai hal. IoT dapat dimanfaatkan di berbagai bidang, salah satunya adalah bidang pertanian. Pada bidang ini IoT dapat digunakan untuk memantau dan mengatur berbagai hal untuk menunjang pertanian. Pada penelitian ini akan dibuat suatu peralatan yang digunakan untuk monitoring dan kontrol sistem irigasi berbasis IOT. Single Board Computer Banana Pi digunakan sebagai prosesor utama yang terhubung dengan jaringan internet yang mengirim data dari sensor ke pengguna. Alat ini akan dilengkapi beberapa divais transduser yang meliputi sensor kelembaban, kamera, dan katup elektronik. Pengguna menerima data tersebut melalui aplikasi pada telepon genggam berbasis android. Jenis telepon ini sering digunakan masyarakat umum sehingga mudah dalam pengaplikasian nya. Peralatan ini diharapkan dapat membantu petani untuk mengatur sistem irigasi dari jarak jauh dan memantau kondisi lahan pertanian sehingga lebih efisien dan dapat meningkatkan hasil panen.
\end{abstract}

Kata Kunci-Arduino, Banana Pi, Internet of Things, Kelembaban, Sistem Irigasi.

\section{PENDAHULUAN}

J UMLAH manusia yang semakin betambah menyebabkan kebutuhan pangan yang ikut bertambah. Irigasi adalah usaha untuk penyediaan dan pengaturan air untuk menunjang pertanian dan perkebunan [1]. Pertanian merupakan sumber merupakan sumber utama dalam kebutuhan pangan. Dalam pertanian pengaliran air atau sistem irigasi sangat berpengaruh pada hasil pertumbuhan tanaman. Sehingga debit air perlu diperhatikan agar tidak berlebihan dan kekurangan. Debit air yang kurang akan berpengaruh pada pertumbuhan tanaman sedangkan debit air yang berlebihan akan berpengaruh pada ketersediaan sumber air.

Metode irigasi tradisional kurang mampu untuk melakukan pengaliran air yang tepat dan cepat. Petani harus menyiram tanaman satu persatu secara manual. Tanah juga memiliki kemampuan menyimpan air yang berbeda beda sehingga perlu diperhatikan kelembabannya. Tetapi petani sulit memperhatikan kondisi kelembaban tanah karena membutuhkan waktu yang lebih lama. Sehingga memperbesar kemungkinan beberapa tanaman tidak dapat tumbuh dengan baik yang menyebabkan berkurang nya hasil panen. Kesulitan memperhatikan kondisi kelembaban tanah juga mengakibatkan penggunaan air yang tidak tepat. Penggunaan air yang berlebihan akan mempengaruhi ketersediaan sumber air yang semakin menurun.

Tugas akhir ini bertujuan untuk menciptakan sistem irigasi berbasis internet of things [2][3], dan [4]. Pada sistem ini petani dapat memonitoring kondisi kelembaban tanah dan mengkontrol debit air yang akan disiram pada tanaman Sehingga meningkatkan hasil panen dan mengoptimalkan penggunaan air.

Sistem ini menggunakan sensor kelembaban tanah atau higrometer [5][6]yang akan di proses di Single Board Computer (SBC) Banana Pi [7]. SBC yang terhubung dengan internet akan mengirimkan data yang didapat dari sensor ke basisdata firebase [8]. Kemudian petani yang menggunakan aplikasi pada ponsel android dapat mengakses data sensor pada basisdata tersebut. Digunakan aplikasi pada ponsel android untuk memudahkan petani melihat kondisi tanah. Selain itu petani dapat melakukan kontrol jarak jauh untuk mengatur debit air yang disiram ke tanah.

\section{URAIAN PENELITIAN}

\section{A. Sistem Irigasi Tetes}

Menurut peraturan pemerintah No. 23 / 1998 tentang irigasi, bahwa irigasi adalah usaha penyediaan dan pengaturan air untuk menunjang pertanian dan perkebunan [9].

Pada penelitian ini digunakan sistem irigasi tetes. Sistem ini menggunakan pipa yang ditempatkan langsung di tanaman atau dekat dengan akar. Pipa dilubangin sesuai kebutuhan air yang akan disiram ke tanaman. Sistem irigasi tetes ini mempunyai kelebihan dibanding sistem irigasi lain yaitu penggunaan air yang lebih sedikit, memudahkan petani saat musim kemarau, dan tidak perlu dilakukan penyiraman tanaman satu persatu.

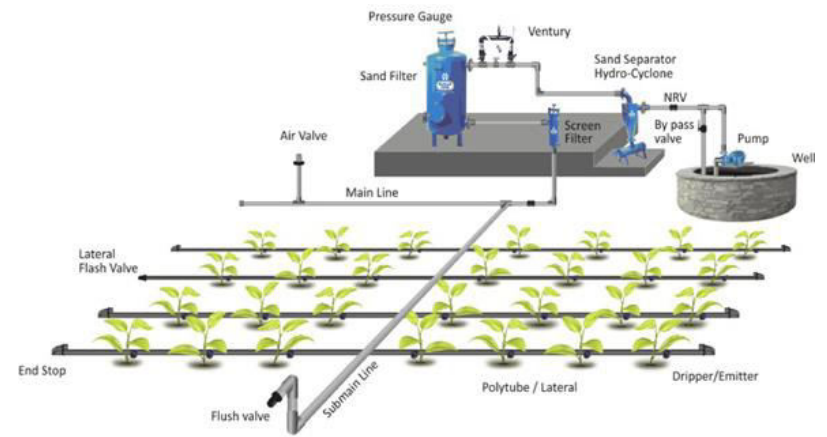

Gambar 1. Sistem irigasi tetes. 


\section{B. Internet of Things}

Secara umum Internet of Things (IoT) adalah suatu konsep menghubungkan perangkat pintar dengan perangkat pintar yang lain baik digunakan untuk bertukar data maupun untuk keperluan pengendalian melalui internet. Diperjalananya kini, konsep IoT sudah banyak digunakan pada objek di sekitar kita. Diperkirakan pada tahun 2020 dala 50 miliar objek yang terhubung dengan Internet [10]. Meski telah digunakan pada banyak perangkat untuk menunjang kehidupan sehari-hari, Internet of Things belum memiliki definisi yang baku.

\section{Sensor Kelembaban YL 69}

Sensor Higrometer merupakan sensor resistif. Sensor ini terdiri dari dua elektrode yang nantinya akan membaca kelembapan disekitarnya, sehingga arus melewati dari satu elektrode ke elektrode yang lain. Besar nilai arus dipengaruhi oleh besar kecilnya resistansi akibat kelembapan yang berada disekitar elektrode. Jika resistansi besar maka kelembapan dari tanah kecil, sedangkan jika resistansi kecil maka arus yang melewati elektrode semakin banyak dan menunjukkan bahwa kelembababan tinggi [11]. Sensor ini juga dilengkapi rangkaian comparator.

\section{Arduino Nano}

Arduino nano merupakan board mikrokontroller berbasis Atmega328p. Arduino Nano memiliki 14 buah digital pin yang dapat digunakan sebagai input atau outp ut. Pin-pin tersebut bekerja pada tegangan $5 \mathrm{~V}$. Arduino sendiri didukung dengan IDE pemrogramannya dengan bahasa pemrograman C. Dalam penelitian ini arduino nano akan digunakan sebagai sensor node.

\section{E. Banana Pi M3}

Banana pi merupakan Single Board Unit yang dapat digunakan untuk berbagai keperluan membuat projek elektronik. Banana Pi m3 dilengkapi dengan processor octacore, dengan kapaistas ram 2gb, penyimpanan eMMC sebesar $8 \mathrm{gb}$. Banana pi $\mathrm{m} 3$ dilengkai dengan fitur wifi, bluetooth, 2 slot usb, koneksi hdmi, SATA, dan lain lain

\section{F. Database Firebase}

Firebase merupakan platform pengembang aplikasi mobile dan aplikasi web. Firebase menyediakan produk penyimpanan database yang bersifat realtime. Platform firebase memiliki banyak library yang memungkinkan untuk mengaksesnya melalui layanan Android, IOS, Javacript, Java, dan masih banyak lagi. Untuk menyingkronkan data yang disimpan, firebase menyediakan Application Programing Interface (API) terdiri dari beberapa fitur yang dapat dikonfigurasi dan disesuaikan dengan masing-masing kebutuhan [12]. API pada firebase menggunakan protokol Server-Sent Event dengan membuat koneksi HTTP untuk menerima push notifikasi dari server. Firebase merupakan platform dibawah perusahaan Google.

\section{G. Android}

Digunakan aplikasi pada android untuk memudahkan pengoperasian. Untuk membuat aplikasi android dapat menggunakan berbagai compiler seperti cordova, android studio, xamarin, dan lain lain. Dengan telepon genggam berbasis android pengoperasian Iot akan menjadi lebih mudah. Arduino Nano

\section{H. Katupu Elektronik}

Katup elektronik berguna untuk mengalirkan air sesuai kebutuhan. Dengan input tegangan DC $12 \mathrm{~V}$. Katup ini memiliki tekanan 0.02-0.8 mpa dengan ukuran pipa $6 \mathrm{~mm}$. katup kemudian diambungkan dengan pipa agar dapat menjadi sebuah sistem irigasi. Pipa kemudian dilubangi untuk menjadi sistem irigasi tetes.

\section{Relay}

Relay adalah salah satu komponen elektronik yang memanfaatkan induksi medan elektromahnetik yang digunakan untuk menghubunkan dan memutus suatu rangkaian.Saat penghantar dialirkan listrik maka akan timbul medan magnet. Medan magnet tersebut akan menginduksi logam ferromagnetis atau logam yang mudah terinduksi medan elektromagnetis. Logam ferromagnetis kemudian akan menjadi magnet sementara saat terinduksi oleh penghantar yang dialirkan arus listrik.Magnet tersebut kemudian akan menarik kontak sehingga menyambungkan suatu rangkaian. Pada relay terdapata 3 pin dimana pin pertama dan kedua bersifat Normally Open dimana kondisi kontak saat relay mati adalah tersambung dan Normally Close dimana posisi kontak akan tersambung ketika ditarik oleh logam ferromagnetik yang menjadi magnet sementara.

\section{J. Server}

Server adalah sebuah sistem komputer yang menyediakan jenis layanan (service) tertentu dalam sebuah jaringan komputer. Server didukung dengan prosesor yang bersifat scalable dan RAM yang besar, juga dilengkapi dengan sistem operasi khusus, yang disebut sebagai sistem operasi jaringan (network operating system). Server yang digunakan adalah Apache2[13].

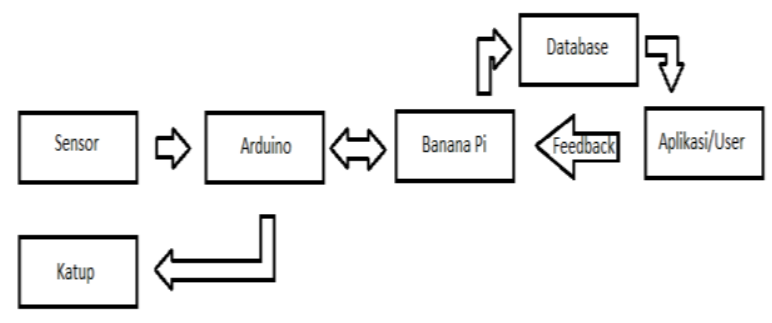

Gambar 2. Diagram Blok Sistem.

\section{PERANCANGAN SISTEM}

\section{A. Diagram Blok Sistem}

Pada diagram diatas dapat dilihat bahwa sistem bekerja diawali dengan pengambilan nilai yang didapat sensor lalu di ubah ke dalam bentuk persen agar mudah dipahami. Nilai tersebut kemudian dikirim ke banana pi secara serial untuk 
kemudian di kirim ke database. Pengguna dapat mengakses data tersebut melalui perangkat android. Dengan aplikasi android pengguna dapat mengatur kelembapan tanah dengan membuka dan menutup katup dari aplikasi.

\section{B. Sensor Kelembaban YL 69}

Pada penelitian ini digunakan sensor kelembaban tanah dengan 2 probe. Sensor ini memiliki output analog dan digital. Pada penelitian ini digunakan output analog untuk dapat dilihat nilai tegangannya. Sensor ini dapat menerima input DC dengan range $3.3-5 \mathrm{~V}$. Pada datasheet nilai output analog dapat menentukan kondisi kelembaban tanah seperti pada tabel 1. Karena sensor diberi tegangan $5 \mathrm{~V}$ makan pembacaan maksimal arduino adalah 1023.

\section{Arduino Nano}

Dalam tugas akhir ini digunakan arduino nano sebagai mikrokontroler yang akan menerima nilai sensor dan diubah kedalam bentuk persentase. Digunakan arduino nano karena tugas yang diberikan tidak terlalu berat dan arduino nano memilki bentuk yang lebih kecil. Berikut pin yang digunakan pada arduino nano.

Tabel 1.

Output Sensor

\begin{tabular}{ccccc}
\hline \hline Item & Kondisi & Min & Max & Unit \\
\hline V & - & 3.3 & 5 & V \\
I & - & 0 & 3.5 & $\mathrm{~mA}$ \\
V Output & Supply 5V & 0 & 4.2 & $\mathrm{~V}$ \\
ADC & Tanah Kering & 0 & 300 & $/$ \\
& Tanah Lembab & 300 & 700 & $/$ \\
& Air & 700 & 950 & $/$ \\
\hline \hline
\end{tabular}

Tabel 2.

Penggunaan Pin Arduino

\begin{tabular}{ccl}
\hline \hline No & Pin & \multicolumn{1}{c}{ Fungsi } \\
\hline 1 & USB & Menghubungkan arduino dengan banana pi \\
2 & A0 & Menghubungkan arduino dan sensor \\
3 & $5 \mathrm{~V}$ & Sumber 5 volt sensor \\
4 & GRND & Ground sensor \\
\hline \hline
\end{tabular}

Tabel 3.

PENGGUNAAN PIN BANANA PI

\begin{tabular}{ccl}
\hline \hline No & Pin & \multicolumn{1}{c}{ Fungsi } \\
\hline 1 & Pin 7 (GPIO 4) & Mengatur Kondisi Relay \\
2 & Pin 6 (Ground) & Ground pada relay \\
3 & Pin 4 (5V) & Sumber untuk relay \\
\hline \hline
\end{tabular}

\section{Banana $P i$}

Digunakan Banana Pi sebagai pengirim nilai pada sensor ke database. Banana Pi terhubung dengan arduino nano dengan komunikasi serial. Banana Pi menggunakan sistem operasi Ubuntu Mate. Banana PI juga berfungsi sebagai pengatur katup melalui GPIO yang terhubung dengan relay. Kondisi relay akan mempengaruhi katup. Saat relay berkondisi Normally Open katup tertutup, sedangkan saat kondisi Normally close katup terbuka.

\section{E. Perangkat Lunak Arduino}

Perangkat lunak pada Arduino bertugas untuk dua hal yaitu, pembacaan nilai sensor dan mengkalibrasi data sensor sehingga menjadi bentuk GWC (Gravimetric Water Content) kemudian dikirim ke banana pi melalui komunikasi serial. Berikut flow chart program untuk arduino.

\section{F. Perangkat Lunak Banana Pi}

Perangkat lunak pada raspberry pi berguna untuk menerima data lalu dikirimkan ke database melalui koneksi internet. Database yang digunakan adalah google Firebase.

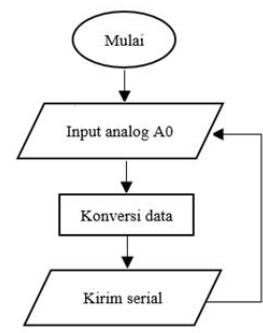

Gambar 3. Diagram Blok Sistem

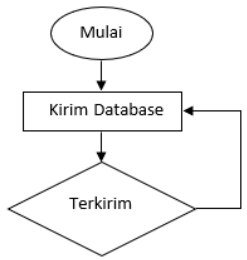

Gambar 4. Diagram Blok Sistem

\section{G. Perangkat Lunak Aplikasi dan Server}

Perangkat lunak pada Arduino bertugas untuk dua hal yaitu pembacaan nilai sensor dan mengkalibrasi data sensor sehingga menjadi bentuk GWC (Gravimetric Water Content) kemudian dikirim ke banana pi melalui komunikasi serial. Flow chart program untuk arduino dapat dilihat pada Gambar 5.

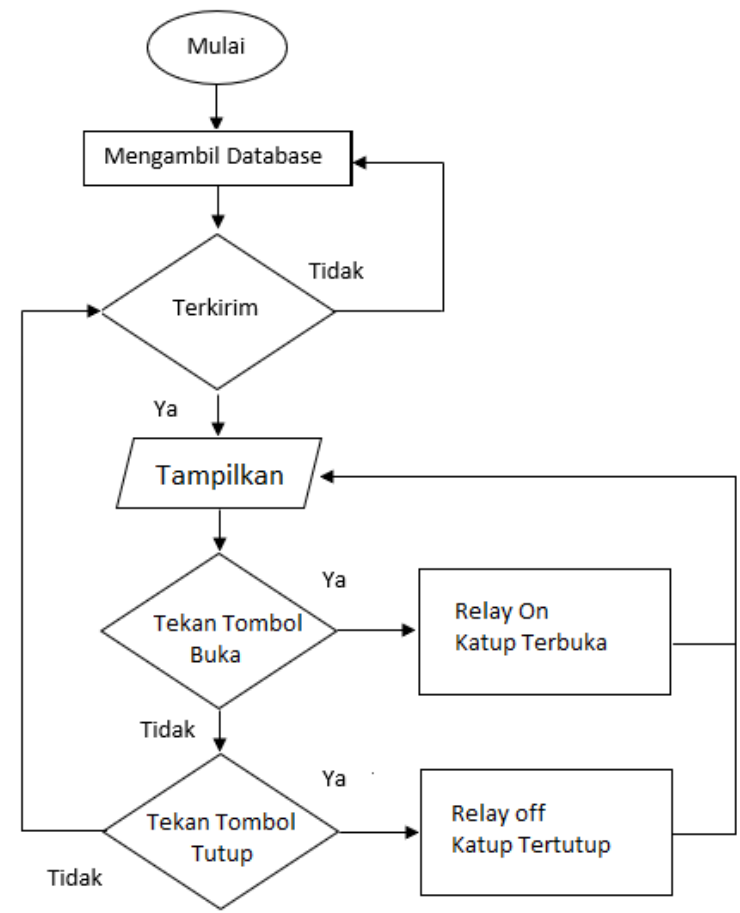

Gambar 5. Diagram blok sistem. 
Perhitungan Nilai GWC

\begin{tabular}{ccccc}
\hline \hline No & Berat (gr) & Air $(\mathrm{ml})$ & Sensor & GWC \\
\hline 1 & 109 & - & 824 & - \\
2 & 112 & 2.5 & 577 & 11.5 \\
3 & 114 & 5 & 345 & 19.2 \\
4 & 116 & 7.5 & 283 & 26.9 \\
5 & 119 & 10 & 266 & 38.4 \\
\hline \hline
\end{tabular}

\section{PENGUJIAN DAN ANALISIS}

\section{A. Pengujian dan Kalibrasi Sensor kelembaban}

Kalibrasi dilakkukan dengan mengukur nilai GWC (Gravimetric Water Content). Nilai GWC didapat dengan menghitung berat tanah saat kering dan berat tanah saat ditambah air. Perhitungan dapat menggunakan persamaan dibawah.

$$
\text { GWC }=\frac{\text { Berat tanah basah }- \text { berat tanah kering }}{\text { berat tanah kering }} \times 100
$$

Nilai GWC didapat seperti pada tabel 4. Kemudian nilai GWC dan nilai sensor akan digunakan untuk mendapatkan persamaan linier menggunakan fitur Trendline pada Microsoft Excel. Hasil didapat seperti Gambar 6.

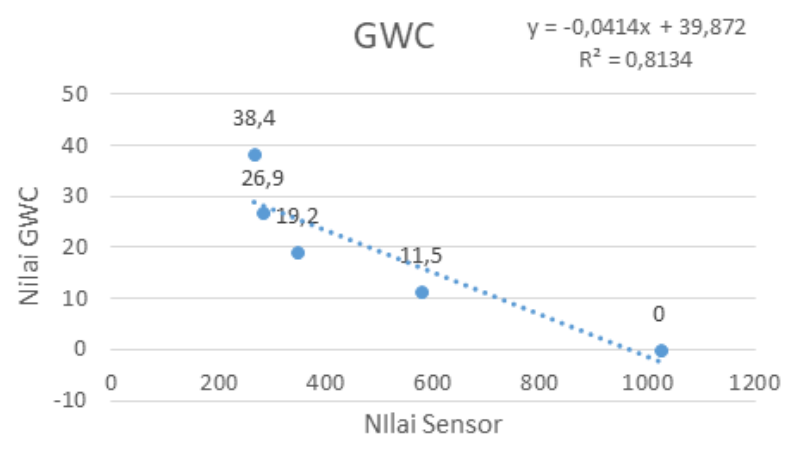

Gambar 6. Grafik Persamaan GWC.

\section{B. Pengujian komunikasi serial dan databse}

Persamaan linier yang didapat kemudian dimasukkan pada program arduino. Kemudian arduino mengirim data tersebut ke Banana Pi melalui komunikasi serial. Pada komunikasi serial antara arduino dan banana pi terdapat data yang tidak sempurna dalam hal ini ada huruf yang hilang Komunikasi yang telah dilakukkan dapat dilihat pada Gambar 7 dan 8 .

NilaiSensor : 1023
NilaiSensor : 1023
NilaiSensor : 1023
NilaiSensor : 1023
NilaiSensor : 1023
NilaiSensor : 1023
NilaiSensor : 1023
NilaiSensor : 1023
NilaiSensor : 1023
NilaiSensor : 1023
NilaiSensor : 1023
NilaiSensor : 1023
NilaiSensor : 1023
NilaiSensor : 1023
NilaiSensor : 1023
NilaiSensor : 1023
NilaiSensor : 1023
NilaiSensor : 1023
NilaiSensor : 1023
NilaiSensor : 1023

$$
\begin{aligned}
& \text { Persentase Kelembaban : } \infty_{\%} \\
& \text { Persentase Kelembaban : } \infty_{0} \\
& \text { Persentase Kelembaban : } \propto_{8} \\
& \text { Persentase Kelembaban : } \infty_{8} \\
& \text { Persentase Kelembaban : } \infty \\
& \text { Persentase Kelembaban : } \infty_{0} \\
& \text { Persentase Kelembaban : } \infty_{0} \\
& \text { Persentase Kelembaban : } \infty \\
& \text { Persentase Kelembaban : } \infty_{8} \\
& \text { Persentase Kelembaban: } \\
& \text { Persentase Kelembaban: } \\
& \text { Persentase Kelembaban: } \mathscr{O}_{0} \\
& \text { Persentase Kelembaban: } \infty_{0} \\
& \text { Persentase Kelembaban : } \infty_{0} \\
& \text { Persentase Kelembaban: } \propto \mathscr{s}^{\circ} \\
& \text { Persentase Kelembaban : } \propto_{s} \\
& \text { Persentase Kelembaban : } O s \\
& \text { Persentase Kelembaban: } \infty_{0} \\
& \text { Persentase Kelembaban : } \infty_{0} \\
& \text { Persentase Kelembaban : } \%
\end{aligned}
$$

Gambar 7. Data sensor pada Arduino.

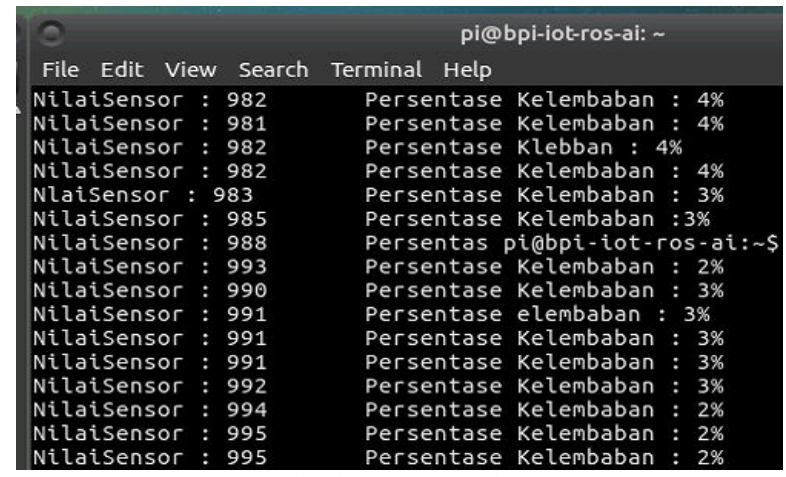

Gambar 8. Data sensor yang diterima Banana Pi.

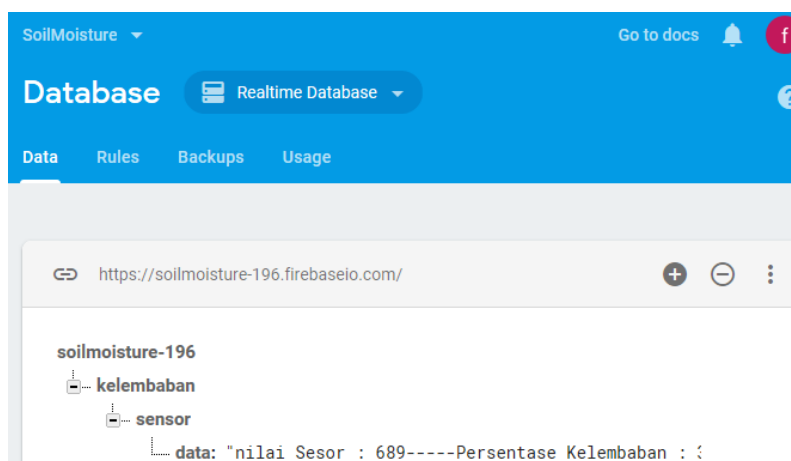

Gambar 9. Tampilan data dalam basis data Firebase

Data tersebut kemudian akan dikirim oleh banana pi ke basis data firebase menggunakan internet dengan script python. Data dikirim ke child kelembaban, sensor dan data. Tampilan data pada firebase dapat dilihat pada gambar 9 .

\section{Pengujian Katup air}

Pengujian dilakukan untuk mengetahui debit air yang dialirkan oleh pipa ke deipper. Pengujian dilakkukan menggunakan sendok takar dan stopwatch. Hasil didapat dripper mengeluarkan air sebanyak $5 \mathrm{ml} /$ menit.

\section{Realisasi Aplikasi Android}

Aplikasi android yang telah dibuat akan menampilkan nilai kelembaban tanah dan pilihan untuk membuka dan menutup katup air. Terdapat juga tampilan kondisi katup terbuka atau tertutup sehingga pengguna dapat mengetahui kondisi katup. Tampilan aplikasi dapat dilihat pada Gambar 10.

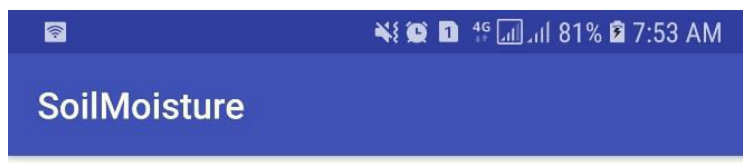

Kelembaban : $23 \%$

KATUP AIR :

TUTUP BUKA

KATUP : TERBUKA

Gambar 10. Tampilan aplikasi android. 


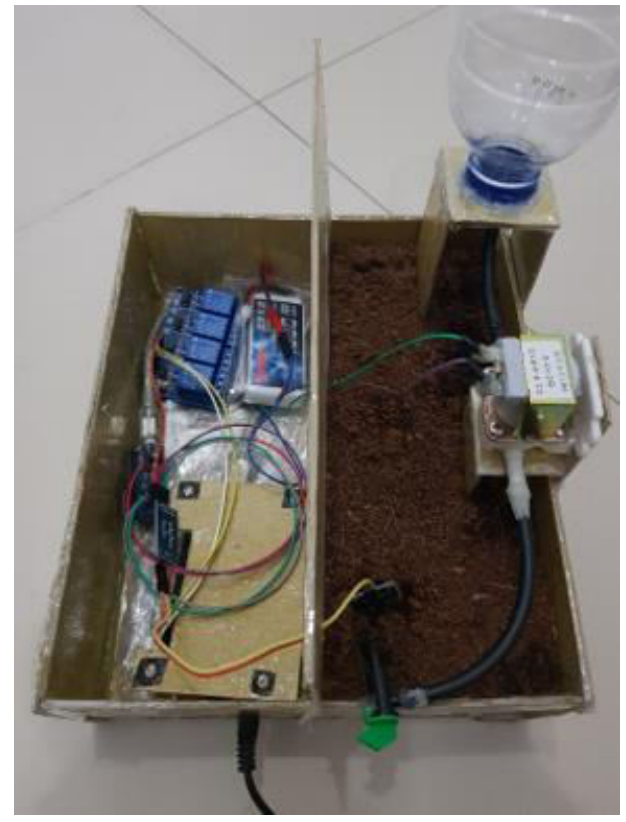

Gambar 11. Realisasi sistem.

\section{E. Realisasi Sistem}

Sistem ditempatkan pada box dengan panjang $25 \mathrm{~cm}$, lebar $21 \mathrm{~cm}$, dan tinggi $8 \mathrm{~cm}$. box terbuat dari bahan karton dengan tebal $2 \mathrm{~mm}$. terdapat sekat untuk memisahkan tanah dan perangkat keras sistem. Sumber air berupa botol yang terhubung dengan pompa melalui pipa. Sisi lain dari pompa terhubung dengan pipa yang menghubungkan pompa dengan dripper. Sensor diletakkan berdekatan dengan dripper untuk pembacaan kelembaban tanah yang terkena air dripper. Hasil realisasi dapat dilihat pada gambar 11 .

\section{KESIMPULAN}

Pada penelitian ini telah dibuat alat untuk monitoring dan kontrol pada sistem irigasi berbasis IoT menggunakan Banana Pi. Konsep IoT diterapkan pada Single Board Computer Banana Pi M3, basis data Firebase, dan aplikasi android.
Pembacaan nilai sensor dan kontrol katup elektronik sangat bergantung pada koneksi internet. Aplikasi dan sistem harus menggunakan koneksi internet yang sama. Pada penelitian ini terdapat huruf yang tidak terkirim dalam komunikasi serial maupun pada basisdata sehingga tampilan pada aplikasi akan tidak lengkap beberapa saat. Dripper yang digunakan mengeluarkan air dengan debit $5 \mathrm{ml} / \mathrm{menit}$.

\section{DAFTAR PUSTAKA}

[1] Pemerintah Republik Indonesia, "Peraturan Pemerintah No. 23/1998 Tentang Irigasi," 1998.

[2] M. Dzukifli, M. Rivai, and Suwito, "Rancang Bangun Sistem Irigasi Tanaman Otomatis menggunakan Wireless Sensor Network," J. Tek. ITS, vol. 5, no. 2, 2016.

[3] M. Gumelar, M. Rivai, and Tasripan, "Rancang Bangun Wireless Electronic Nose Berbasis Teknologi Internet of Things," J. Tek. ITS, vol. 6, no. 2, 2017.

[4] H. Irawan, M. Rivai, and F. Budiman, "Rancang Bangun Wireless Sensor Network pada Pendeteksi Dini Potensi Kebakaran Lahan Gambut Menggunakan Banana PI IoT," J. Tek. ITS, vol. 6, no. 2, 2017.

[5] R. Setiawan, M. Rivai, and Suwito, "Implementasi Analog Front End Pada Sensor Kapasitif Untuk Pengaturan Kelembaban Menggunakan Mikrokontroller STM32,” J. Tek. I, 2017.

[6] M. Rivai, K. Sambodho, and D. Purnomo, "Identification of Levee Strength For Early Warning System Using Fuzzy," in International Conference on Information, Communication Technology and System, 2014.

[7] Banana Pi, "Banana Pi 3." [Online]. Available: http://www.bananapi.org/m3.html.

[8] Google Firebase, "Features - Powerful backend services for your app." [Online]. Available: https://www.firebase.com/features.html.

[9] Geografi.org, "Sistem sistem irigasi di indonesia," 2016. [Online]. Available: $\quad$ www.geografi.org/2016/11/sistem-sistem-irigasi-diindonesia.html.

[10] GSMA, "Understanding the internet of things (IoT)."

[11] Circuitstoday.com, "Moisture sensing automatic plant watering system using 8051." [Online]. Available: http://www.circuitstoday.com/automatic-plant-watering-systemusing-8051.

[12] B. Nicolas and B. Lucie, "Real Time Database : Firebase."

[13] Apache2 server, "Apache http server project," 2018. [Online]. Available: https://httpd.apache.org/ . 